\title{
Diffusion Bonding/Superplastic Forming of Ti-6Al-6V-2Sn/SUS 304 Stainless Steel/Ti-6Al-6V-2Sn
}

\author{
J.S. Shyu and T.H. Chuang
}

\begin{abstract}
The superplasticity of the Ti-6Al-6V-2Sn alloy for different temperatures was evaluated by single-sheet free blowing. The optimal superplastic temperature for the Ti-6Al-6V-2Sn alloy was found to be $850^{\circ} \mathrm{C}$. Diffusion bonding of Ti-6Al-6V-2Sn and 304 stainless steel was carried out in a vacuum. The interface of both bonded alloys was examined by EPMA. The concentration profile of Ni exhibited a peak at the interlayer and a valley adjacent it, whereas that of $\mathrm{Cr}$ exhibited a peak where Ni showed the valley. $\mathrm{X}$-ray diffraction (XRD) analyses showed that the $\mathrm{Fe}_{2} \mathrm{Ti}$, NiTi, and $\mathrm{CrMn}$ intermetallic compounds and the $\mathrm{Cr}$ element formed at the interface. The thickness profiles of the blown specimens were measured and compared with theoretical calculations.
\end{abstract}

\section{Keywords}

diffusion bonding, dome height, free blowing, interface, line scan, superplastic forming, thickness profile, Ti-6Al-6V-2Sn

\section{Introduction}

A DUPLEX phase titanium alloy, Ti-6Al-6V-2Sn was developed to improve the strength of the Ti-6Al-4V alloy. With more $\beta$ phase stabilizer elements of $\mathrm{V}$, the $\beta$ phase transformation temperature of Ti-6Al-6V-2Sn $\left(948^{\circ} \mathrm{C}\right)$ is lower than that of Ti$6 \mathrm{Al}-4 \mathrm{~V}\left(1000^{\circ} \mathrm{C}\right)$. The suitable superplastic forming temperature of Ti-6Al-4V is from about 900 to $950{ }^{\circ} \mathrm{C}$ (Ref 1 ). The application of superplastic forming/diffusion bonding for Ti$6 \mathrm{Al}-4 \mathrm{~V}$ has been widely used $(\operatorname{Ref} 2,3)$, but there have been few reports on superplasticity in Ti-6Al-6V-2Sn. This study evaluates the superplasticity of this titanium alloy.

For the superplastic forming of a thin circular diaphragm clamped at the periphery and subjected to one-sided hydrostatic pressure, Ragab (Ref 4) showed that the thickness distribution of the material is:

$$
S / S_{\mathrm{o}}=1 /\left(1+\sigma Y_{\mathrm{p}} / a^{2}\right)^{2}
$$

where $S$ is instantaneous thickness of sheet, $S_{\mathrm{o}}$ is initial thickness of sheet, $\sigma$ is height of bulge annulus or section during free bulging, $Y_{\mathrm{p}}$ is height of bulge during free bulging, and $a$ is die aperture radius or half-width. See Fig. 1.

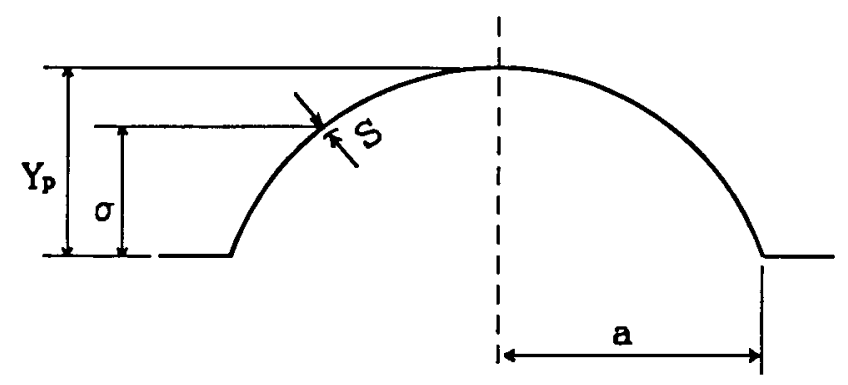

Fig. 1 Geometry of deformation during free bulging of circular sheet

J.S. Shyu and T.H. Chuang, Institute of Materials Science and Engineering, National Taiwan University, Taipei, Taiwan, R.O.C.
The theoretical models of Ragab are compared with experimental results.

For practical use in industry, it is difficult to achieve the required combination of properties in a single material, for example, strength and corrosion resistance. One way to solve this problem is to use bimetallic materials; i.e., steel of high strength metallurgically bonded to a thin corrosion-resistant clad alloy (Ref 5). When the bonding was finished, Hinotani showed that $\mathrm{TiNi}_{3}$, $\mathrm{TiNi}$, and $\mathrm{Ti}_{2} \mathrm{Ni}$ were formed across the $\mathrm{Ti} / \mathrm{Ni}$ interface (Ref 6 ) and that in $\mathrm{Ti} / \mathrm{Fe}$ couples, intermetallic compound layers of $\mathrm{TiFe}_{2}$ and $\mathrm{TiFe}$ were formed. B. Aleman et al. (Ref 7) carried out a detailed examination of the bonding interface of AISI $316 \mathrm{~L}$ stainless steel and Ti-6Al-2Mo-4Zr-2Sn alloy. They found that several interphases, including $\mathrm{Fe}_{2} \mathrm{Ti}$, FeTi, and others, formed at the interface. In the present study, diffusion bonding of Ti-6Al-6V-2Sn and 304 stainless steel was carried in vacuum by hot press. The interface after bonding was examined by electron probe microanalysis (EPMA). Furthermore, the applicability of the diffusion bonding/superplastic forming technique for manufacturing of Ti-6Al-6V-2Sn hollow spheres was evaluated.

\section{Experimental Procedures}

Ti-6Al-6V-2Sn plates, $1 \mathrm{~mm}$ thick, were cut by a laser beam into two diameters: 28 and $38 \mathrm{~mm}$. (The actual forming diameters are 20 and $30 \mathrm{~mm}$.)

First, the optimal superplastic temperature of Ti-6Al-6V2 Sn was tested by single-sheet free blowing for the plate with a diameter of $38 \mathrm{~mm}$ (Fig. 2). Second, the peripheries of two Ti$6 \mathrm{Al}-6 \mathrm{~V}-2 \mathrm{Sn}$ sheets were diffusion bonded by inserting a 304 stainless steel ring between them (Fig. 3a). The height of the 304 stainless steel ring was $6 \mathrm{~mm}$. Further, for the plates of two diameters, the outer diameters of the rings were 38 and $30 \mathrm{~mm}$,

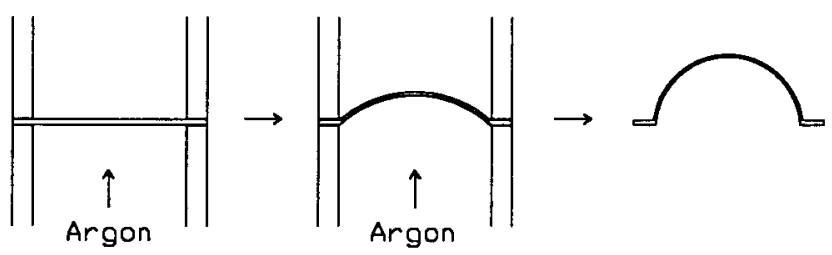

Fig. 2 Free blowing of Ti-6Al-6V-2Sn sheet 
and the inner diameters were 28 and $20 \mathrm{~mm}$. Diffusion bonding was conducted in a $25 \mathrm{~kW}, 20 \mathrm{kHz}$ induction vacuum furnace under the conditions of $890^{\circ} \mathrm{C}$ for $1 \mathrm{~h}$ under $2000 \mathrm{psi}$ in $10^{-5}$ torr vacuum and furnace cooling (Fig. 3b). The bonding interface between Ti-6Al-6V-2Sn and 304 stainless steel was then analyzed by EPMA. After bonding, a hole was drilled in the 304 stainless steel ring, and a stainless steel tube was then welded to it (Fig. 3c). The bonded components were then superplastically formed by free blowing with argon pressure in a vacuum furnace (Fig. 3d). Under various blowing conditions, the deformation heights and thickness distributions of the Ti-6Al$6 \mathrm{~V}-2 \mathrm{Sn}$ sheets following the diffusion bonding/superplastic forming process were measured.

\section{Results and Discussion}

For the single-sheet free blowing of $38-\mathrm{mm}$-diam Ti-6Al$6 \mathrm{~V}-2 \mathrm{Sn}$ (the actual forming diameter was $30 \mathrm{~mm}$ ), Fig. 4 shows the forming dome heights for various forming temperatures and forming times under the blowing condition of $120 \mathrm{psi}$ argon pressure $(1 \mathrm{MPa}=145 \mathrm{psi})$. For $15 \mathrm{~min}$, the dome height increased with the temperature. The surfaces of the specimens were rough after blowing above $950^{\circ} \mathrm{C}$. This phenomena was attributed to the extensive grain growth that occurred during superplastic forming above the $\beta$ transformation temperature of Ti-6Al-6V-2Sn $\left(948{ }^{\circ} \mathrm{C}\right)$. Thus, temperatures above $948{ }^{\circ} \mathrm{C}$ are unsuitable for superplastic forming of Ti-6Al-6V-2Sn. As the forming time increased, the difference in the dome heights for various forming temperatures became more obvious. The two curves representing the data of 30 and 60 min show that $850^{\circ} \mathrm{C}$ was the optimal superplastic forming temperature for Ti-6Al-6V-2Sn.

The diffusion-bonded Ti-6Al-6V-2Sn/304 stainless steel interfaces were analyzed by EPMA. Figure 5 shows the line scan profiles of the major elements of both alloys. A comparison of the profiles of $\mathrm{Ni}$ and $\mathrm{Cr}$ in Fig. 5(d) shows that there was a peak in the profile of $\mathrm{Ni}$ on the interlayer formed at the interface and

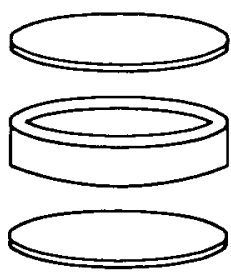

(a)
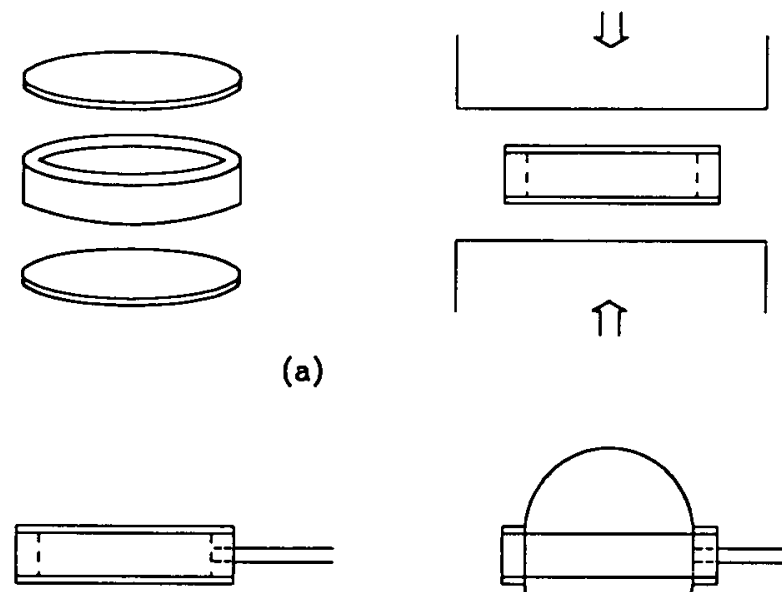

(c) (b)

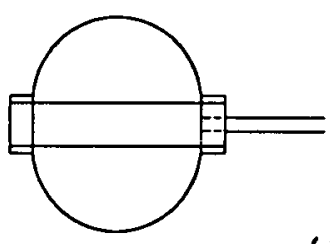

(d)
Fig. 3 Manufacturing processes of the Ti-6Al-6V-2Sn hollow sphere that, beside the peak, there was a valley in the profile near the 304 stainless steel side. The $\mathrm{Cr}$ profile, however, exhibited a peak at the same position where $\mathrm{Ni}$ formed a valley. Some bonded specimens fractured at the bonding interface. These fractures were presumably due to the thermal stress, which resulted from the difference of the thermal expansion coefficients of the bonding components. The newly formed, two fractured surfaces were flat enough for the XRD analysis. Figure 6(a) shows the $\mathrm{x}$-ray spectrum for the fractured surface on Ti-6Al$6 \mathrm{~V}-2 \mathrm{Sn}$. $\mathrm{Fe}_{2} \mathrm{Ti}$ and NiTi formed. Figure $6(\mathrm{~b})$ shows the spectrum for the fractured surface on 304 stainless steel. $\mathrm{Cr}$ and $\mathrm{CrMn}$ formed. (The Mn content of 304 stainless steel is $0.98 \mathrm{wt} \%$.)

The diffusion-bonded Ti-6Al-6V-2Sn/304 stainless steel/Ti$6 \mathrm{Al}-6 \mathrm{~V}-2 \mathrm{Sn}$ components were then free blown at $850^{\circ} \mathrm{C}$ with various pressures and for various time periods. Figure 7(a) and (b) show the average forming dome heights of the spherelike component, 30 and $20 \mathrm{~mm}$ diam, blown under different conditions. Two typical spherical products with different diameters are shown in Fig. 8.

For the thickness measurement, the specimens were cut symmetrically across the center, and the thicknesses of the Ti$6 \mathrm{Al}-6 \mathrm{~V}-2 \mathrm{Sn}$ plates were measured and plotted along the diameter. Figure 9(a) and (b) show the thickness distributions of the superplastically blown Ti-6Al-6V-2Sn hemispheres for the 30 $\mathrm{mm}$ and $20 \mathrm{~mm}$ diam spherelike components. The thickness profiles calculated from the Ragab equation are also presented. For all the specimens, the measured values were higher than the calculated ones, except those near the ends of the diameter. The deviation of the experimental results from the theoretical calculations arises from the assumption that the material of the plate clamped at the periphery is fixed. That is, the volume of the plate that underwent superplastic deformation remained constant. However, in a real situation, due to the compression of

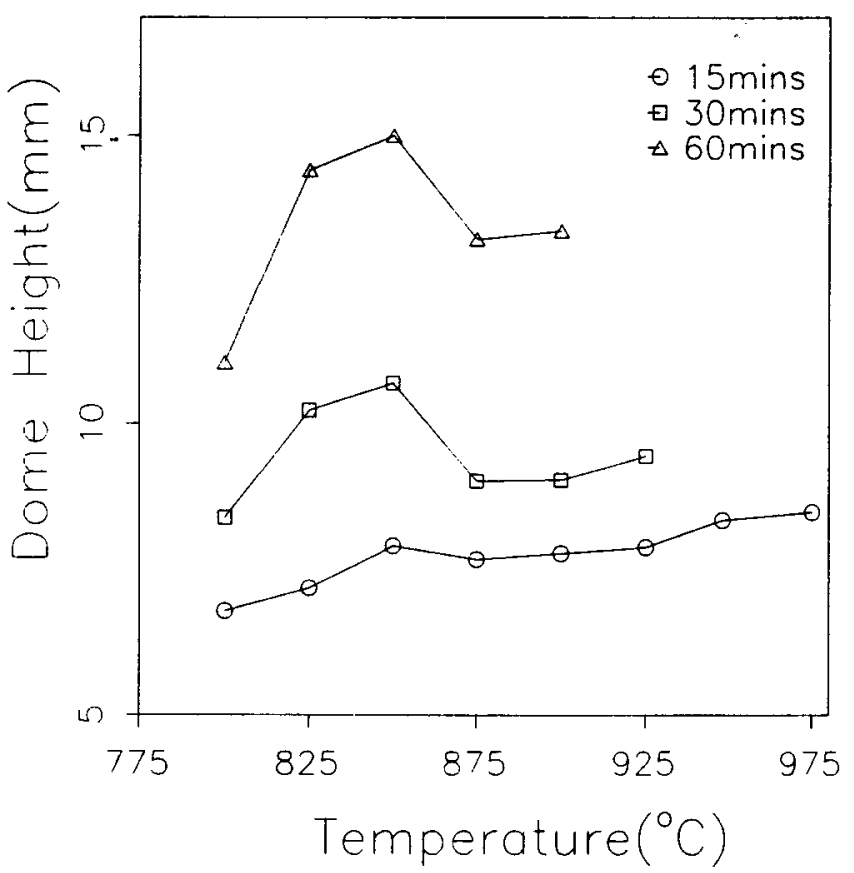

Fig. 4 The single-sheet forming dome heights of Ti-6Al-6V$2 \mathrm{Sn}$ blown at various temperatures with 120 psi for 15,30 , and $60 \mathrm{~min}$ 
Ti6A16V2Sn

304

Ti

A1

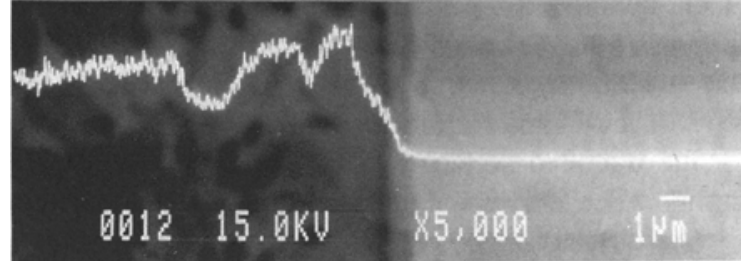

(a)

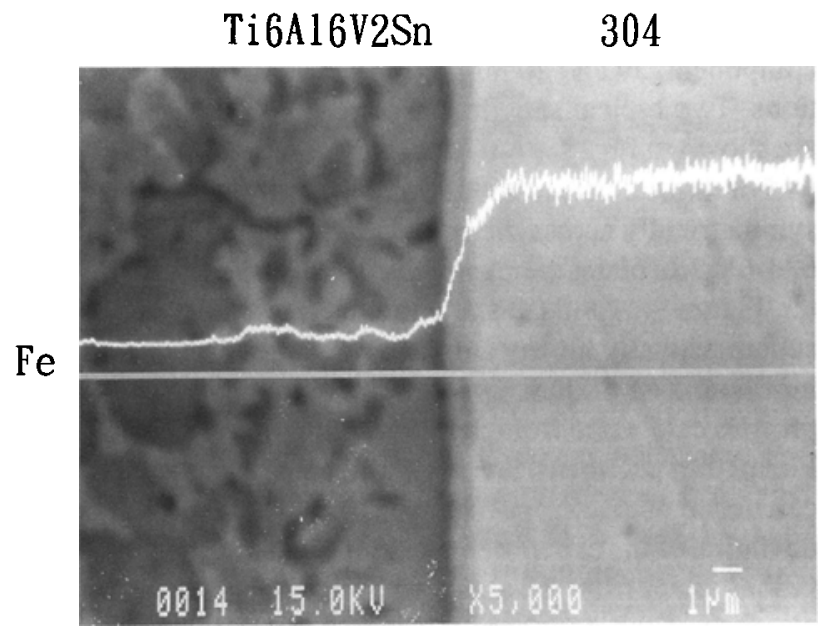

(c)

Fig. 5 EPMA line scannings for (a) $\mathrm{Ti}$ and $\mathrm{Al}$, (b) $\mathrm{V}$ and $\mathrm{Sn}$, (c) $\mathrm{Fe}$, and (d) $\mathrm{Ni}$ and $\mathrm{Cr}$ across the Ti-6Al-6V-2Sn/304 stainless steel interface

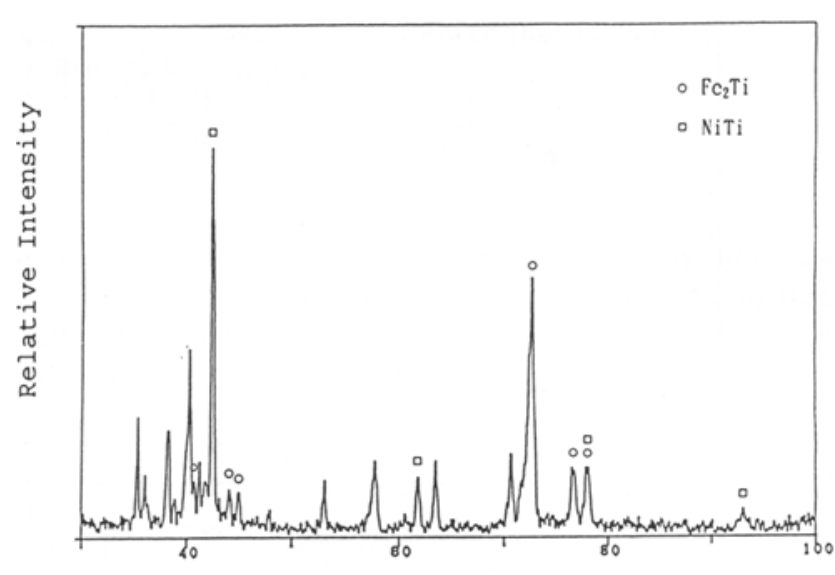

$2 \theta$ (degree)

(a)

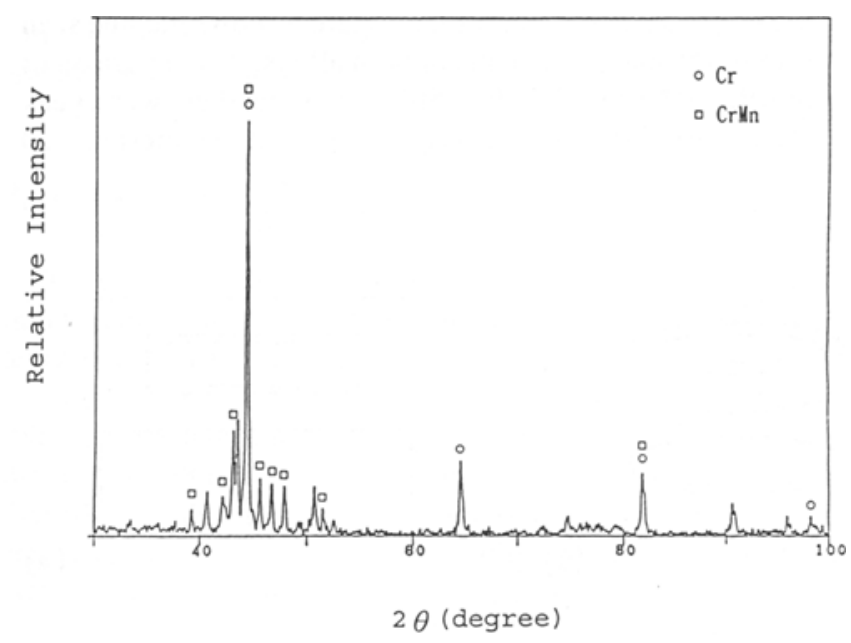

(b)

Fig. 6 XRD patterns from fractured surfaces of Ti-6Al-6V-2Sn / 304 stainless steel couple. (a) Ti-6Al-6V-2Sn side. (b) 304 stainless steel side

the molds and the drag of the part that is superplastically deforming, the material of the plate clamped at the periphery can- not avoid flowing gradually toward the center. Thus the volume is increased. This makes the thickness profile smoother. 


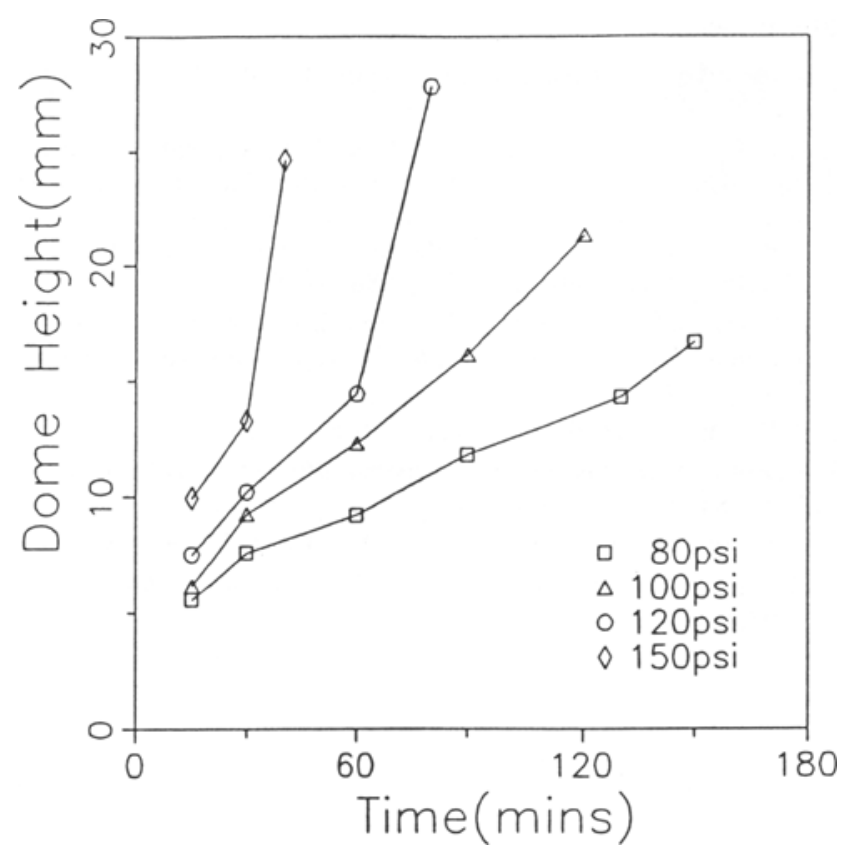

(a)

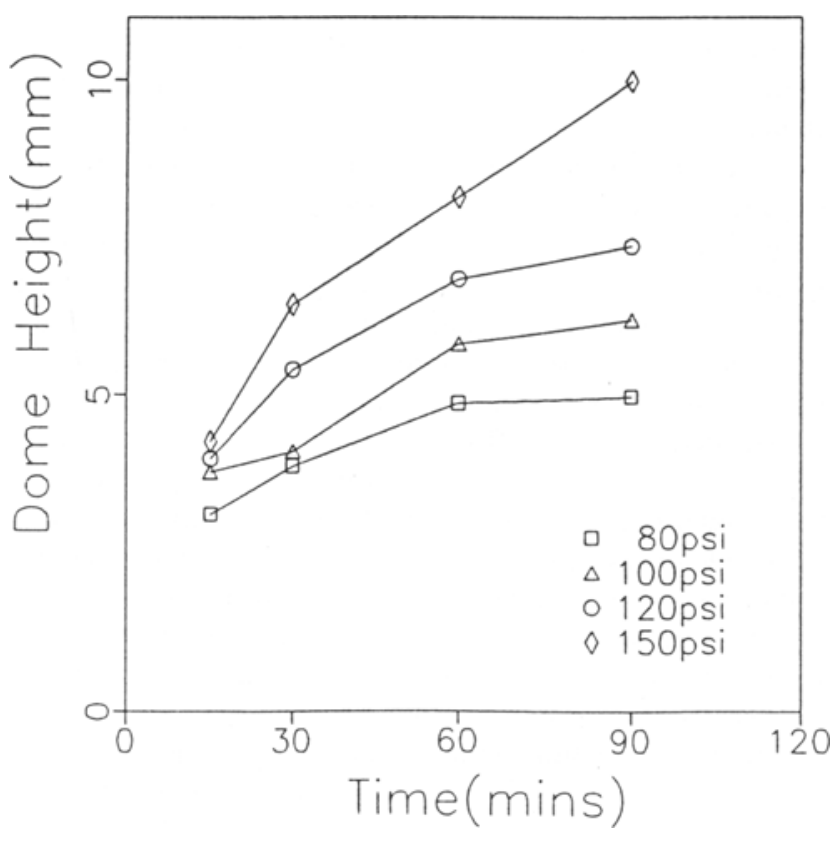

(b)

Fig. 7 The forming dome heights of Ti-6Al-6V-2Sn hemispheres with diameters of (a) $30 \mathrm{~mm}$ and (b) $20 \mathrm{~mm}$

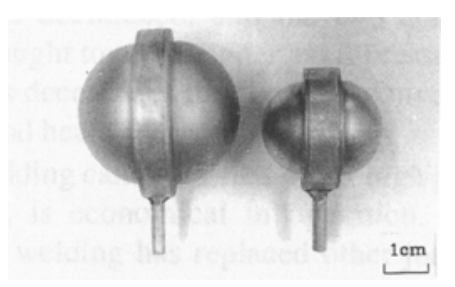

Fig. 8 Ti-6Al-6V-2Sn/304 stainless steel/Ti-6Al-6V-2Sn hollow sphere with diameters of 30 and $20 \mathrm{~mm}$ after diffusion bonding and superplastic forming

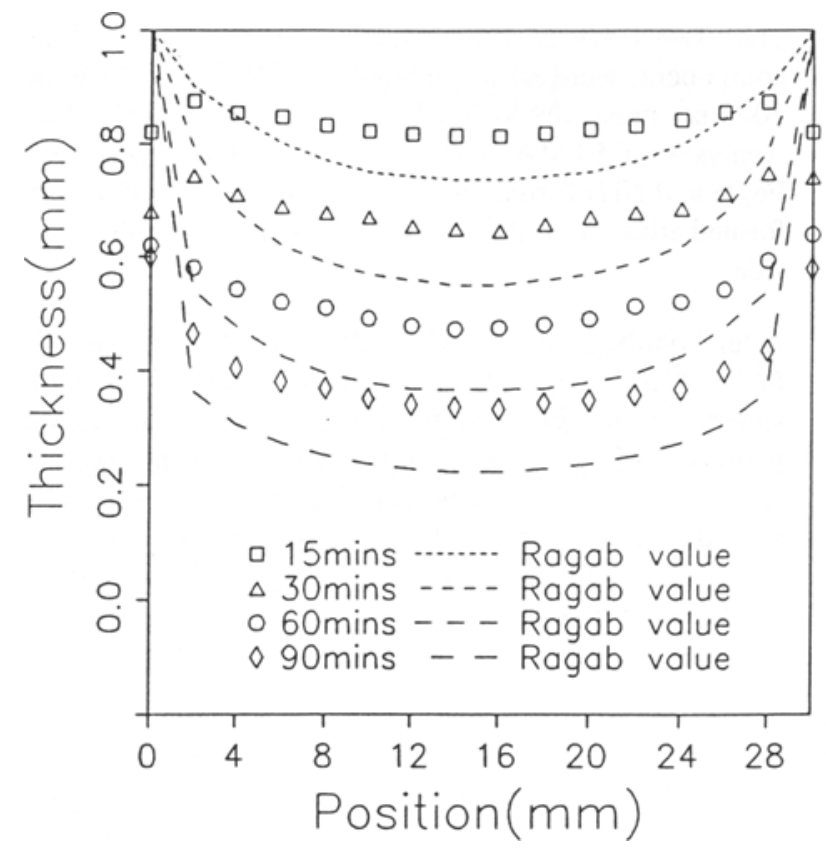

(a)

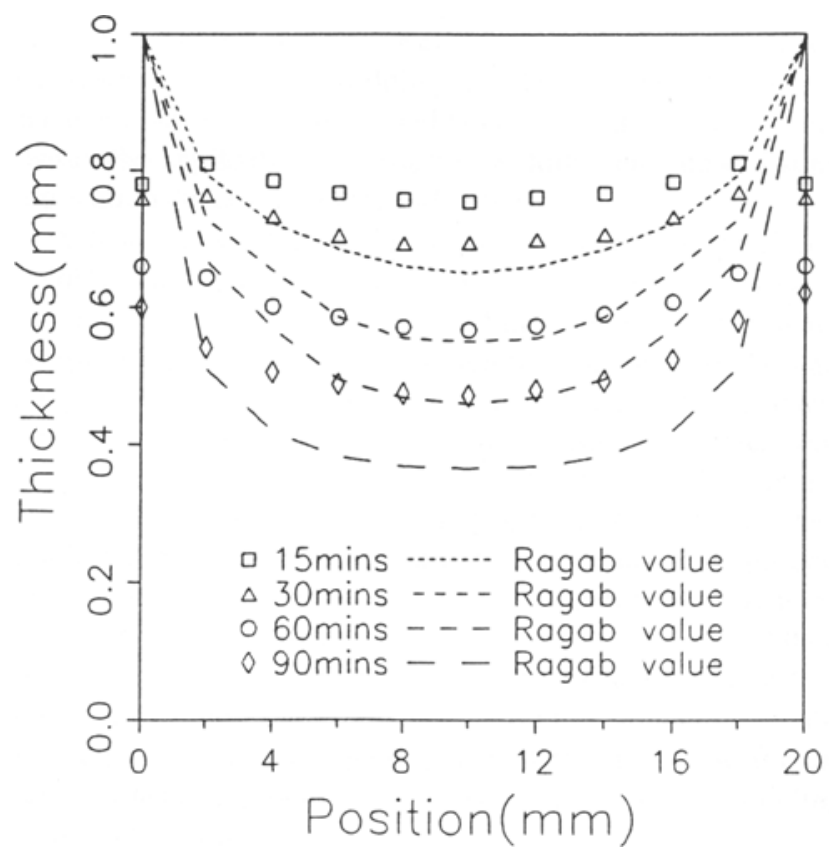

(b)

Fig. 9 The thickness distributions of the Ti-6Al-6V-2Sn hemispheres free blown at $850^{\circ} \mathrm{C}$ for various periods of time and the results calculated by using Ragab's equation. (a) $30 \mathrm{~mm}$ diam hemispheres blown with $100 \mathrm{psi}$. (b) $20 \mathrm{~mm}$ diam hemispheres blown with 120 psi

\section{Conclusions}

- $\quad 850^{\circ} \mathrm{C}$ was evaluated and found to be the optimal superplastic forming temperature for Ti-6Al-6V-2Sn by free blowing of single sheet. 
- The Ti-6Al-6V-2Sn/304 stainless steel/Ti-6Al-6V-2Sn components were diffusion bonded at $890^{\circ} \mathrm{C}$ for $1 \mathrm{~h}$ under 2000 psi pressure. An interlayer formed at the interface. Analyses of EPMA, line scans, and XRD showed that $\mathrm{Fe} 2 \mathrm{Ti}$ and NiTi formed in the interlayer, and $\mathrm{Cr}$ and $\mathrm{CrMn}$ formed adjacent to the interlayer on the 304 stainless steel side.

- After bonding, the Ti-6Al-6V-2Sn/304 stainless steel/Ti6Al-6V-2Sn components were superplastically blown to a spherical shape with various pressures and for various time periods at $850^{\circ} \mathrm{C}$. The thickness profiles of the spherical specimens with different forming dome heights were smoother than those calculated by the equation deduced by Ragab due to the central flow of the material during superplastic deformation.

\section{References}

1. A. Arieli and A. Rosen, Metall. Trans. A, Vol 8 (No. 10), 1977 , p 1591

2. H.E. Friedrich, R. Furlan, and M. Kullick, Superplastic Forming/Diffusion Bonding on the Way to the Production Stage for Ti and $\mathrm{Al}$, Proc. Conf. on Superplasticity and Superplastic Forming, C.H. Hamilton and N.E. Paton, Ed., Blaine, Aug 1988, The Metallurgical Society of AIME, 1988, $\mathrm{p} 649$

3. R.C. Davis, D.M. Royster, and T.T. Bales, Superplastically Formed Titanium Hat-Stiffened Panels, NASA Tech. Briefs, Vol 14 (No. 1), 1990, p 63-64

4. A.R. Ragab, Met. Technol., Vol 10, 1983, p 340

5. H. Kato, M. Shibata, and K. Yoshikawa, Mater. Sci. Technol., Vol 2, 1986, p 405

6. S. Hinotani, The Sumitomo Search, No. 44, Dec 1990, p 346

7. B. Aleman, I. Gutierrez, and J.J. Urcola, Mater. Sci. Technol., Vol 9 , $1993, \mathrm{p} 633$ 